\title{
ADVANCED DISTANCE LEARNING FOR TRAINING NATIONAL PEACEKEEPING FORCES
}

\author{
Andrij Ivashchenko and Kateryna Synytsya
}

\section{Ukraine and Peacekeeping}

Ukraine takes an active part in peace support activities since June 1992. Since then, more than 20000 Ukrainians participated in conflict regulations in various parts of the world, which was important to strengthen the good political image of the country.

In general, the scale of Ukrainian participation in peacekeeping is steadily growing, covering more countries and regions, involving more militaries and military observers, and setting up more complex and challenging tasks for participants. Currently, more than 3000 Ukrainian peacekeepers are participating in ten different missions around the world (see Figure 1), including operation in Republic of Moldova, Kosovo, Georgia, Lebanon, Sierra-Leone, Democratic Republic of Congo, Ethiopia, Eritrea, Liberia, and Republic of Iraq. Due to its active position, Ukraine is now among the top 10 countries that contribute to the UN peacekeeping missions; Ukraine is the largest "exporter" of peacekeeping forces among European countries.

Unfortunately, peacekeeping operations may lead to casualties. In the last years, Ukraine lost 27 peacekeepers, including four persons in Iraq.

Readiness to act in dangerous situations depends on personnel experience and preparatory professional and psychological training. Thus, it is critical to provide appropriate training, including study of mission-specific and region-specific issues. To this purpose traditional training may and should be enhanced through use of modern tools, including information and communications technologies for learning, training, and assessment. 


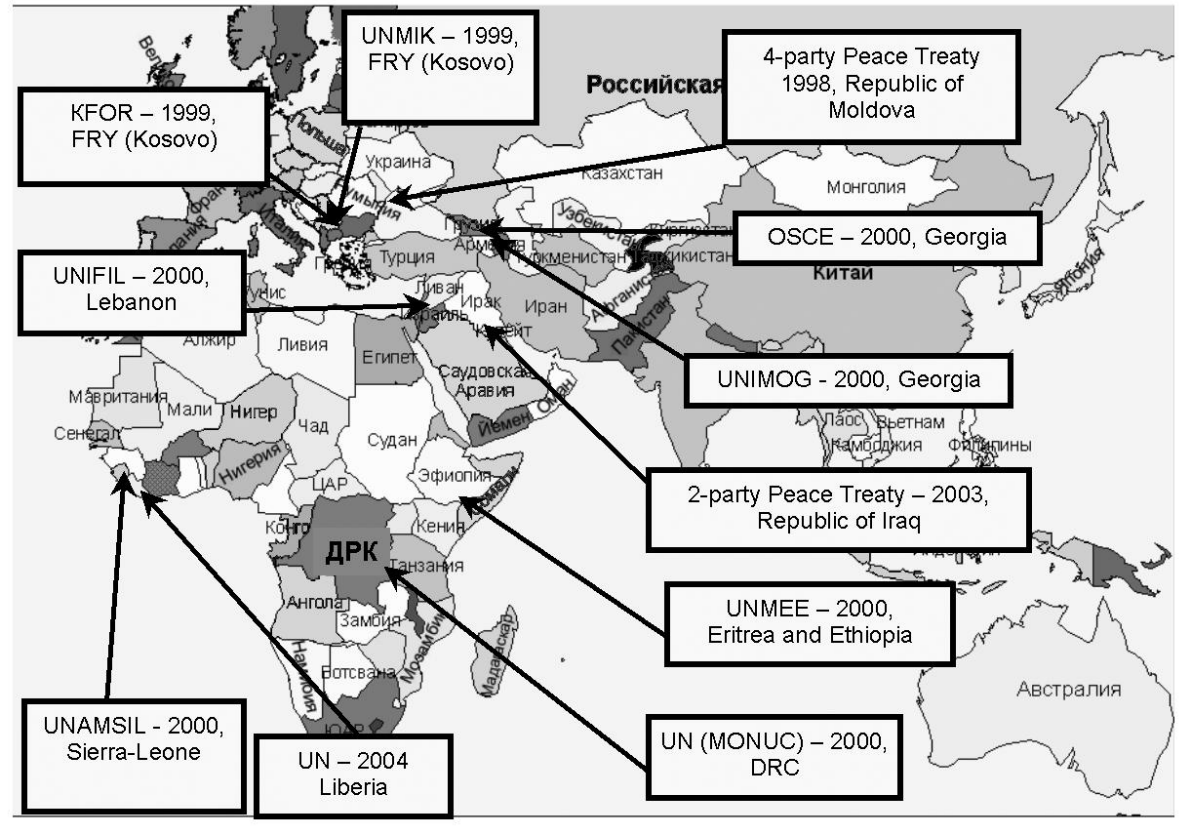

Figure 1: Participation of Ukraine in peacekeeping operations (as of February 1, 2004).

More and more personnel are involved in the international operations. According to our forecasts, the number of Ukrainian peacekeepers participating in various missions may amount up to 5000 in 2007. To meet the $\mathrm{UN}^{1}$ and $\mathrm{NATO}^{2}$ recommendations on training personnel to ensure rotation every six months, Ukraine needs to have no less than 15000 trained peacekeepers in its active reserve.

A close study of the rotations of the national contingent demonstrated that under current contractual terms, only 25-30 percent of all peacekeepers volunteered to continue their participation in the mission upon rotation. In case of regions with unusual climate conditions, such as Central Africa, this amount is lower than 5 percent. These numbers show that most of the volunteers that should be prepared for a mission do not have any peacekeeping experience. There may be also insufficient number of experts to share their experience in performing a specific mission in a certain region. Due to the limited secondary involvement of the peacekeepers and inability to offer better financial, insurance, social and other conditions under the contract, it is necessary to find new technologies and approaches to ensure effective training. 
Thus, main reasons to explore ADL-based approach for training peacekeepers are:

- Growing participation in peacekeeping operations and the need to simultaneously train personnel located in different regions of Ukraine;

- Variety of trainee's experience and its relevancy, in particular, large percentage of personnel with no relevant experience;

- Need to ensure readiness to unforeseen situations, were competence is lifecritical.

\section{Technology-supported Training Approach}

To transform unique experience, acquired in years, into systemic knowledge that may be shared among the parties involved, including peacekeepers, decision-makers, and politicians, to determine new forms of participation in peacekeeping operations in the future, one needs to go beyond military and political aspects of peacekeeping. ${ }^{3}$ It is critical to consider other issues in more detail, such as organization and management of efficient and purposeful personnel training of those who are intended for participation in a peacekeeping mission. In particular, the issues of formation and training of specific (sub-) units and their officers, reducing learning cycles, simulation and modeling of personnel activities in new and unforeseen situations. The capability to find effective solutions is important during the whole operation, starting from forwarding reconnaissance groups, further during deployment of main forces and rotations, and up to transfer of functions to local authorities and mission completion. So, training methodology should be aimed at continuous experience building.

The ideas of using learning technologies in peacekeepers' training were first piloted during the training of the 6th Separate Mechanized Brigade to participate in the operation of the international forces to support stability and ensure security in Iraq. 1600 trained peacekeepers started their mission in February 2004 as part of the multinational division "Higher South" in the Polish responsibility sector.

The suggested approach to ADL-supported training was aimed to answer the needs of this specific mission, thus all notations are taken from this particular case. Hence, the brigade corresponds to a total number of trainees. It consists of 4 battalions, that represent separate operational units to be located in different positions during the mission, and a military staff that coordinates and controls the mission activities.

To ensure accelerated training of large number of participants it was suggested to use information technologies at all stages during both preliminary training for the peacekeeping mission and actual participation in the operation. In the core of technological support were the ADL approach and distance learning technologies. Ukraine has a certain experience in developing and using e-learning technologies for University courses and retraining. ${ }^{4}$ However, most of the past projects were devoted 
to the transformation of one or more traditional courses from a stable curriculum to a distance mode. Instructional designers worked with materials that were prepared for students who took a correspondence course, and issues of possible course updates or reconfiguration were not taken into account. Thus, the current project was challenging and innovative for both civilian and military experts in education and training.

Several organizations were involved in the project devoted to IT-supported training for peacekeeping forces. The overall schema of work and interaction is presented on Figure 2, which depicts logical phases of project development. The sequence of these phases corresponds to the training cycle and, thus, the output of each phase of the project is aimed to support a certain training period. Content development and instructional design for each training phase may be performed in parallel; however, it is worth to envisage modifications of the learning material, activities and didactics based on feedback obtained from the course participants and their supervisors during and after the mission. Potential feedback is shown by thin arrows; it corresponds to minor and immediate adjustments, whereas systematic changes and complex upgrades are implemented through the main cycle.

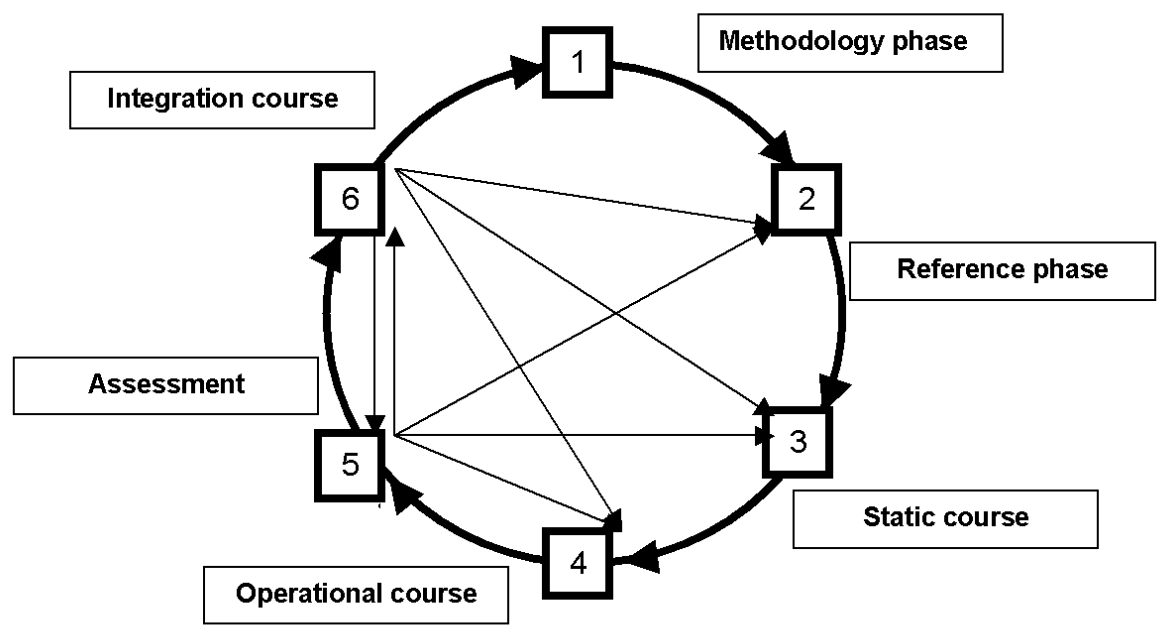

Figure2: Phases of project development. 
The first phase of the project was devoted to creation of general methodology approach and thus required participation of all interested parties. At this phase, the project members defined the problem, structured it into specific tasks, determined the final goal and objectives to be achieved at each stage of the project, proposed some technology solutions and outlined expected results.

Besides, each working group responsible for some specific task of the project presented its approach to the learning material structure, learning activities, assessments, and overall vision of possible interaction with other parts of the project. Based on that, a common scenario for brigade-level training was developed to facilitate specific course creation (Figure 3). At the schema, the brigade-wide learning is indicated by yellow, battalion learning activities are given in blue and training of various specialists for each battalion are shown by violet.
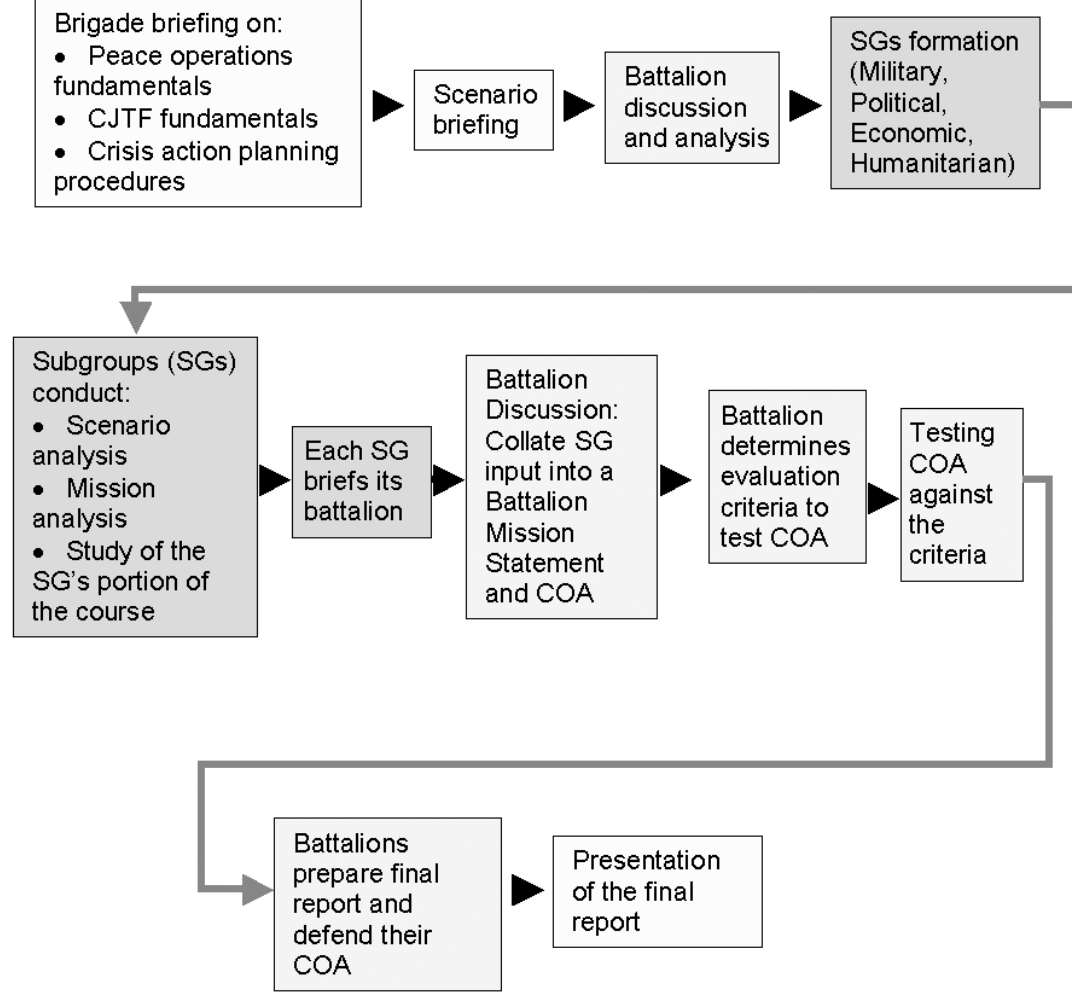

Figure 3: Common scenario for brigade-level training. 


\section{Main Training Phases}

The second (reference) phase of the project was devoted to the development of the distributed database that can be accessed via the Internet or by using military mirror servers within the firewall. The database contains a set of national documents on peacekeeping activities, history of participation of Ukraine in peacekeeping operations, legislative base, requirements to the peacekeeping personnel, etc. ${ }^{5}$ Each candidate for participation in the peacekeeping mission obtained a list of topics to be studied using the database. This recommended study facilitates basic understanding by the potential peacekeepers of their roles and responsibilities, regulations and requirements, and ensure informed decision of the applicants. From the technology viewpoint, this phase was based on existing electronic materials and proven database solutions.

The next two phases address training of the selected applicants for participation in the peacekeeping operation. The need for distance learning technologies at these phases may be better understood when one is aware of the approach to the peacekeepers' selection and training. Let's turn to the 6th Brigade example.

Within the period of preparation of the 6th Brigade for its mission, the longest time was devoted to the selection of volunteers. In fact, Ukraine faced an inevitable transition from traditional methods of recruiting to the use of mobile focal points, as is the experience of countries with fully professional military. Currently, performance of military duties by males over 18 years old is ensured by a permanent network of military contact points, which issue calls for duties, register participants and transport them to the place of duty in coordination with local authorities. This network has been used in the past to attract volunteers for the peacekeeping operations.

The scale of participation of Ukraine in peacekeeping required a new approach and the need for methodological support, advertisement and marketing, as well as participation of legal and military contract experts became obvious. Lack of experience and timely support slowed down the recruiting process, and peacekeeping candidates were arriving irregularly.

Phases "Static course" and "Operational course" are named after types of experience specific for a mission, which may be acquired in a distance mode by selected peacekeeping participants from their locations. It is envisaged that instructors who have participated in the current or in a similar mission will lead distance courses. The courses would start when two thirds of the target personnel has been recruited.

The static course focuses on simple situations, which are considered "static" in a sense that they take place in a specific region, additional external factors are not taken into account and situation does not change until some actions are suggested. The 
content of the course is focused on learning standard recommended procedures. Its purpose is to facilitate acquisition of knowledge and skills to resolve a situation by performing one of the pre-defined roles.

Table 1. Sample topics to be covered by the Static and Operational courses

Static course ( $30 \%$ of time)

Operational course $(70 \%$ of time)

Strategic Background to PSO

Planning for PSO

Changing Nature of PSO

Operational Tasks

Conceptual Approach to PSO

Operational Techniques

Fundamentals and Principles of

Lessons and conclusions from the deployment PSO of the multinational forces; Recommendations on Preventing Military Conflicts and on Training and Employing Multinational Peacekeeping Forces

At the next training phases the trainees consider complex situations. Sample topics that may be covered by Static and Operational courses are listed in Table 1. We should mention that it is not only topics, but rather a kind of competence that should be acquired and learning activities arranged to facilitate acquisition process that differentiate these two courses. Whereas the Static course may be implemented as a typical distance course with interactions limited to the menu-based or elementscombination activities, the operational phase requires communication with instructor, as well as multimedia-rich and interactive material.

The operational course is intended for training participants to resolve complex situations, consider consequences and all related factors, envisage dynamics of the situation, and offer solutions adequate to their resources and timeframe within which the situation should be resolved. It may be viewed as a kind of a game, which covers the dynamics of the situation within several months, and reacts to the participant's actions by changing the situation according to the heuristic rules based on cumulative experience gained by the experts who led the development in similar situations. Each action taken by a participant is a step in this game, and thus requires permanent monitoring of the situation and looking forward for the next step. Unlike the computer-based action games, there is no "safe mode" or possibility to return back to the saved results - the players need to cope with the consequences of their actions. The purpose of this course is to prepare a participant to take responsibility and understand that his own life and the life of his team members may depend on his 
decisions. It is also planned to include some psychological training to help participants cope with realities of the mission.

Thus, the operational course is rather complex and may require longer time for its development. The general schema of training by the Operational course is demonstrated at Figure 4. Participants are presented with description of the situation and are required to offer a plan and its stepwise implementation. During implementation, the situation may change and require correction of plan and actions. The trainee's actions are evaluated and a feedback mechanism offers some complication to the current situation or a next task to solve.

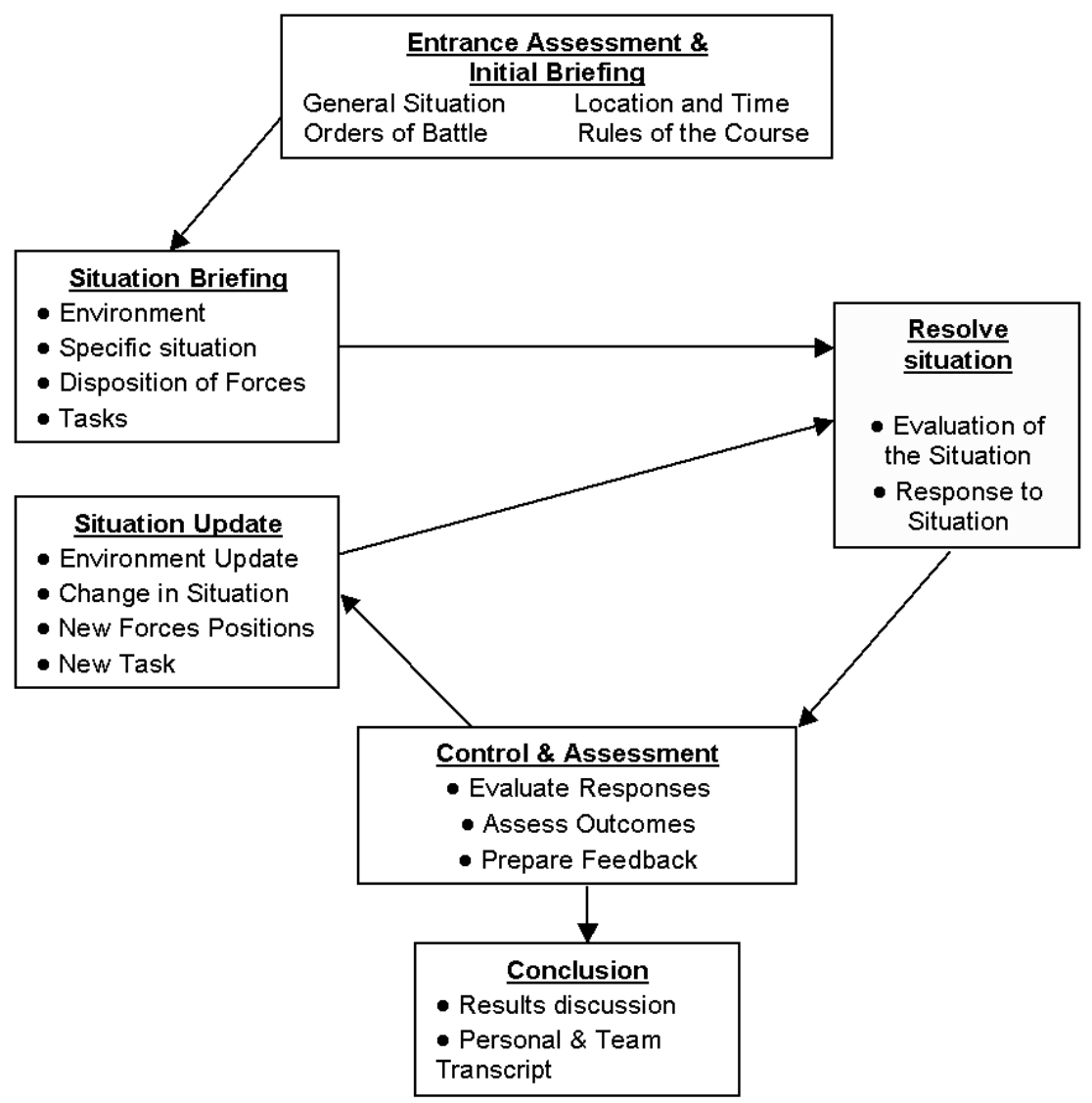

Figure 4: General schema of the Operational course. 
The next training phase is performed at the Yavoriv Training Center in the western part of Ukraine, where future peacekeepers are gathered for team exercises after being trained locally. The focus of training at this phase is on authentic peacekeeping activities and specifically on the coordination of subunits' actions.

Prior to authentic exercises at this stage, the participants are pre-tested to determine the level of their readiness and potential training deficiencies. Thus, IT-based assessments and evaluations may help schedule training activities in the most efficient way. The main goal at this stage is to assess readiness to participate in the peacekeeping mission both for each individual and a team as a whole. ${ }^{6}$ Thus, the assessment should cover 100 percent of the personnel, including those who participated in the initial Static and Operational courses, volunteers who have experience in peacekeeping operations and those who did not complete the initial course and need to catch up with the group. This is the most intensive part of the preparatory stage in a sense of training and feedback on training results. As indicated on Figure 2, assessment results are reported back to the learning content and course developers of phases 2-4 to enhance learning and training.

\section{ICT-based Mission Support}

Upon successful training, the peacekeepers are transferred to the region of their mission. Traditional communication channels delay transformation of the mission information into training examples. The tight rotation schedule restricts exchange of the specific experience between the groups; thus it is important to ensure mechanisms to support decision-making and continuous learning and training of the peacekeepers to enhance their mission performance. The purpose of this support mechanism is twofold. First, it should ensure communication channels, expert evaluation, and registration of all information related to a conflict situation for current decisionmaking and further incorporation of the situation into the bank of mission examples. Second, it should ensure access of the peacekeepers to the learning and training materials to address issues revealed during the Assessment phase and to get training updates on the mission goals, specific situation, international legislative changes, current mandate requirements, etc., thus serving as just-in-time training support.

At this phase of training, which is named "Integration course," participants need to apply all knowledge and skills they acquired to solve authentic tasks. In some cases, similar situations have occurred in the past and necessary procedures to resolve conflict were elaborated and tested. In other cases, expert evaluation and prognostic methods may be applied to novel situations were trusted solutions do not exist.

We expect that at this phase it is important to organize communication and collect feedback from expert groups. Sample group structure is shown at Figure 5. These 
groups provide feedback essential to resolve a conflict situation, and consider it from different viewpoints. Proven solutions as well as potential traps may be recorded and further used in training at the preparatory stage.

Although battalions are distributed over a large territory, they maintain communication, and their experts may take part in the decision-making process. Internet connection via satellite ensures timely access to information and may be used for distance training and support.

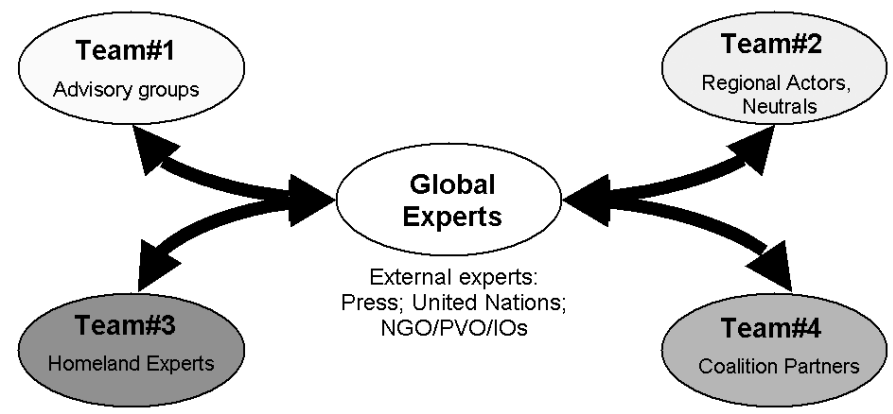

Figure 5: Expert groups supporting decision-making.

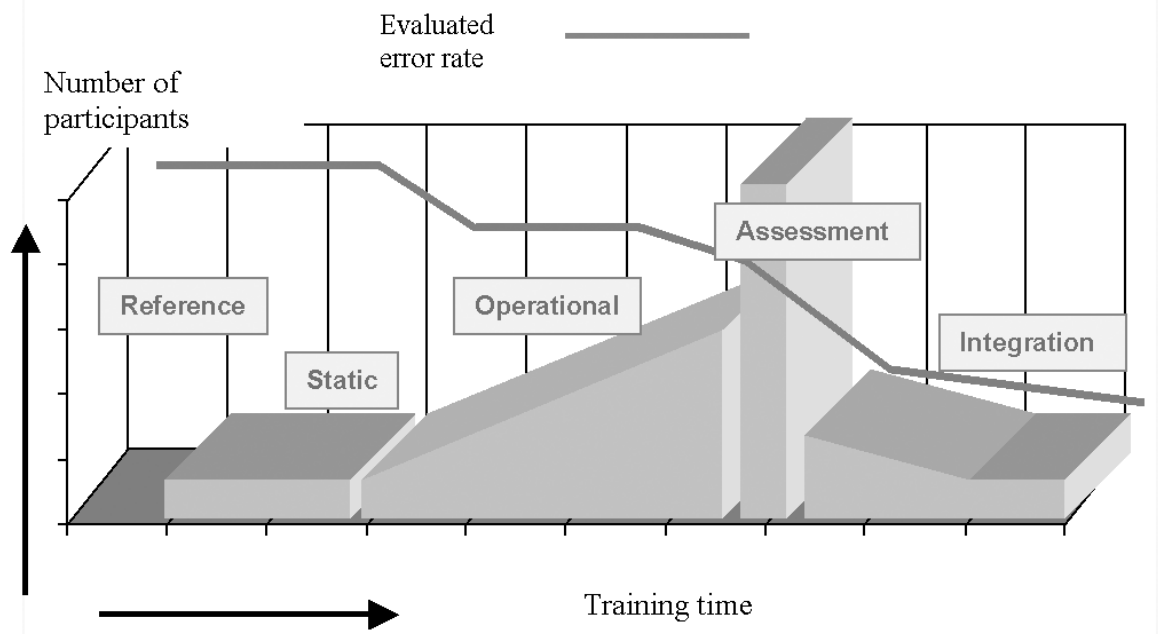

Figure 6: Dynamics of key training features. 


\section{Conclusion}

Although first piloting revealed many technical, management, and administration issues at different layers, preliminary estimations are promising (Figure 6). To be successful this project had to rely on pragmatic approach, extensive reuse of existing materials, and proven technologies. Its modular structure allows for stepwise enlargement and updates, and developers made all efforts to follow technical standards, and specifically the SCORM framework, in order to ensure reusability of specific learning materials.

At the planning stage, the project members indicated general part of the training that is addressed to all peacekeepers, and specific parts, depending on qualification of the trainee, or on specific features of the mission. Specific parts are labeled according to their position in Profession $\mathrm{x}$ Mission Region $\mathrm{x}$ Mission type cube to facilitate their reuse for future mission training. Information pertained to the situations resolved in current mission is also classified and stored for use in training examples. During development of specific modules and elements of the courses, the developers indicated necessary entrance competencies and learning objectives, which facilitate their reuse at the course advancement stage.

\section{Notes:}

$1 \quad$ Peace Support Operations: A Manual (New York, NY: United Nations, 1997)._194 pp.

2 Bi-MNC Directive for NATO Doctrine for Peace Support Operations (Brussels, NATO HQ, October 1998).

3 Timothy L. Thomas, "Preventing Conflict Through Information Technology," Military Review 78, 6 (December 1998 - February 1999): 44-57.

4 Andrij Ivashchenko and Kateryna Sinitsa, "Information Technology for Training Forces of Peacekeeping Operations," in Telematics and Life-Long Learning. Proceeding of the International Workshop TLLL-2001 (Kyiv, Ukraine: IRTC, 2001), pp. 102-104.

5 Some were drawn from documents like Peace Support Operations, Joint Warfare Publication 3-50 (London: Ministry of Defence, 2001).

6 Peace Operations, Field Manual No. 100-23 (Washington, DC: Department of the Army, December 1994), <http://www.dtic.mil/doctrine/jel/service_pubs/fm100_23.pdf> (6 May 2004); Information Operations, Field Manual No. 100-6 (Washington, DC: Headquarters, Department of the Army, August 1996), <http://www.fas.org/irp/doddir/ army/fm100-6/> (6 May 2004).

Colonel Dr. ANDRIJ M. IVASHCHENKO is Director of the Defence Planning Department at the National Research Center for Defence Technologies and Military Security of Ukraine. His research interests include: national security, strategic defence planning, security sector reform, strategic armed forces transformed, peacekeeping operation, information technology for national security. E-mail: ivashchi@ pims.org.

KATERYNA SYNYTSYA, see page 44. 